\title{
Estimativas de parâmetros genéticos e a variabilidade em procedências e progênies de Handroanthus vellosoi
}

Camila Moreira Batista1, Miguel Luiz Menezes Freitas², Marcela Aparecida de Moraes ${ }^{1}$, Antonio Carlos Scatena Zanatto ${ }^{2}$, Pedro César dos Santos ${ }^{1}$, Marcelo Zanata ${ }^{2}$, Mario Luiz Teixeira de Moraes ${ }^{1}$, Alexandre Magno Sebbenn²

'Universidade Estadual Paulista, Faculdade de Engenharia de Ilha Solteira, Av. Brasil Centro, 56, CEP 15385-000, Ilha Solteira, SP, Brasil

${ }^{2}$ Instituto Florestal, Rua do Horto, 931, CEP 02377-000, São Paulo, SP, Brasil

"Autor correspondente:

miguellmfreitas@yahoo.com.br

Termos para indexação:

Conservação ex situ

Espécies arbóreas tropicais

Genética de populações

Genética quantitativa

Index terms:

Ex situ conservation

Tropical tree species

Population genetics

Quantitative genetics

Histórico do artigo:

Recebido em 17/01/2012

Aprovado em 27/08/2012

Publicado em 28/09/2012

doi: 10.4336/2012.pfb.32.71.269
Resumo - O presente estudo objetivou estimar parâmetros genéticos e a variabilidade entre e dentro de procedências, para caracteres silviculturais em um teste de procedências e progênies de Handroanthus vellosoi (Toledo) Mattos estabelecido na Estação Experimental de Luiz Antônio (SP). O teste foi instalado no delineamento experimental de blocos de famílias compactas, com duas procedências (alocadas nas parcelas), seis repetições e sub-parcelas lineares de cinco plantas, totalizando 35 progênies. $\mathrm{O}$ ensaio foi mensurado para os caracteres diâmetro à altura do peito, altura de planta, volume cilíndrico, forma do fuste e sobrevivência aos 24 anos de idade. Diferenças significativas entre procedências foram observadas apenas para o caráter forma do fuste. Pela análise de deviance foram detectadas diferenças significativas para o efeito de progênies para análise conjunta das procedências (população experimental), sugerindo que esta tem alta variação genética e indicando possibilidade de melhoramento genético pela seleção das melhores progênies. A estimativa de herdabilidade em nível individual e média de progênies variaram de baixa a moderada (26\% para DAP, 32\% para altura, 24\% para volume cilíndrico, $27 \%$ para forma do fuste e $46 \%$ para sobrevivência), confirmando a possibilidade de melhoramento genético por seleção e que as procedências tem potencial para responder à pressão de seleção natural.

\section{Estimates of genetic parameters and variability in provenances and progeny of Handroanthus vellosoi}

\begin{abstract}
The present study aimed at estimating genetic parameters and variability among and within provenances for silvicultural traits of Handroanthus vellosoi (Toledo) Mattos, in provenances and progenies test stands, located at the Luiz Antônio Experimental Station (São Paulo State, Brazil). The test was established in the compact family block design, with two provenances (allocated in the plots), six replicates and sub-linear plots of five plants, totalizing 35 progenies. Diameter at breast height (DBH), plant height, cylindrical volume, stem form and survival at 24 years of age were evaluated. Significant differences among the provenances were observed only to the trait stem form. The analysis of deviance showed significant differences among progenies for the joint analysis of the provenances (experimental population), suggesting that the population has high genetic variation and indicating the possibility of genetic improvement by selection of the best progenies. Heritability estimates in individual and family level ranged from low to moderate $(26 \%$ for $\mathrm{DBH}, 32 \%$ for plant height, $24 \%$ for cylindrical volume, $27 \%$ for form and $36 \%$ for survival), confirming the possibility of genetic improvement by selection and that the provenances have potential to respond to the pressure of natural selection.
\end{abstract}




\section{Introdução}

As ações antrópicas têm levado à fragmentação de populações naturais de espécies florestais, gerando risco real de erosão genética e até mesmo de extinção de espécies, especialmente nos biomas tropicais (Pinto et al., 2004). Quando a floresta se torna fragmentada ocorre a diminuição no tamanho das populações e, consequentemente, na sua diversidade genética e no potencial adaptativo das populações arbóreas ali presentes, tornando-as, com este isolamento, significativamente mais vulneráveis a eventos ambientais, demográficos e genéticos.

A conservação dos recursos genéticos, mesmo para aquelas populações que apresentam alta taxa de variabilidade genética e estão fora da lista de espécies ameaçadas de extinção, é de suma importância para as futuras gerações, no que diz respeito ao melhoramento da espécie e ao aproveitamento de genes de interesse específico (Freitas et al., 2006). A aquisição de conhecimentos acerca dos parâmetros genéticos de uma determinada espécie nativa proporciona inúmeras contribuições para o aprimoramento de estratégias de conservação in situ e ex situ.

A espécie Handroanthus vellosoi (Toledo) Mattos é utilizada de forma predatória, pois o seu uso em escala comercial é pequeno e suas sementes ainda são colhidas em populações naturais fragmentadas.

Portanto, medidas devem ser adotadas para a recuperação e regeneração de espécies ameaçadas e para sua reintrodução em seu habitat natural em condições adequadas, sendo estratégias para a conservação ex situ. Segundo Nass et al. (2001) a conservação ex situ é a manutenção de genes ou complexos de genes de indivíduos em condições artificiais, fora do seu habitat natural. Pode ser feita de diferentes formas, como coleções permanentes de pólen, sementes, culturas de tecidos ou coleções de plantas mantidas em campo, de acordo com as características da espécie e a disponibilidade de recursos materiais e humanos.

Para efetiva conservação genética de uma espécie, utilizase o conhecimento prévio de seu sistema de reprodução, estrutura e diversidade genética, no delineamento de estratégias para a recombinação, amostragem e uso do material genético remanescente. Deste modo, as informações podem ser obtidas por meio do uso de marcadores genéticos. No caso de espécies arbóreas, como forma de planejar o uso sustentável e a conservação in situ, programas de conservação enfatizam a determinação dos níveis de variabilidade genética mantidos dentro e entre populações naturais (Kageyama, 1987). Uma das viabilidades técnicas utilizadas para conservação, de acordo com Nanson (1972), é a transformação de testes combinados de procedências e progênies em pomares de sementes por mudas. Esta tranformação é um fator importante no melhoramento de plantas arbóreas, inclusive para as espécies consideradas não industriais, e de múltiplo uso (Haugerud \& Collinson, 1990; Simons, 1992). A seleção dos indivíduos, nos testes de procedência, tem sido feita pelas características fenotípicas e em testes de progênies pela seleção individual.

O presente trabalho objetivou estimar parâmetros genéticos e a variabilidade entre e dentro de procedências de uma população de $H$. vellosoi, com vistas à exploração em futuros programas de melhoramento genético e conservação ex situ.

\section{Material e Métodos}

A espécie Handroanthus vellosoi, conhecido por ipêamarelo, ipê-tabaco, cavatã, ipê-cascudo, ipê-preto, ipêuma, pau-d'arco, ipê-amarelo-da-casca-lisa, ipê-comum, piúva e quiarapaíba, possui altura de $15-25 \mathrm{~m}$, com tronco de 40-70 cm de diâmetro na fase adulta (Lorenzi,1992). Ocorre nos estados de Minas Gerais, São Paulo, Mato Grosso do Sul, Goiás e Rio de Janeiro, principalmente na floresta pluvial. Possui madeira de alta densidade, resistente, de grande durabilidade mesmo em condições adversas, sendo muito utilizada para usos externos, confecção de artefatos torneados, bengalas, carrocerias, tonéis, etc. Também é considerada árvore símbolo do Brasil, por Decreto Federal, e de grande utilidade na ornamentação e no reflorestamento de áreas degradadas (Lorenzi, 1992; Carvalho, 1994). É ótima para o paisagismo em geral, sendo mais apropriada para arborização de parques e praças devido ao seu porte elevado.

Trata-se de uma planta decídua, heliófita ou esciófita, característica da floresta pluvial da mata atlântica e da floresta latifoliada semidecídua. O florescimento ocorre anualmente a partir do mês de julho, prolongando-se até meados de setembro com árvore totalmente despida de folhagem, apesar de produzir relativamente poucas sementes (Lorenzi, 1992; Carvalho, 1994).

\section{Amostragem e delineamento experimental}

Para este estudo, coletaram-se sementes de polinização aberta de 18 árvores matrizes de uma população de Bebedouro e 17 de Mogi Guaçu de H. vellosoi. O experimento foi instalado no ano de 1986, na Estação Experimental de Luiz Antônio, SP, do Instituto Florestal de São Paulo, (21 ${ }^{\circ} 40^{\prime} \mathrm{S}, 47^{\circ} 49^{\prime} \mathrm{W}$ e altitude de $550 \mathrm{~m}$ ). O clima da estação experimental é tropical (Cwa), com 
temperatura média anual do mês mais quente de $22,7^{\circ} \mathrm{Ce}$ do mês mais frio de $17,2^{\circ} \mathrm{C}$, inverno seco e precipitação média anual de $1.280 \mathrm{~mm}$ (Ventura et al., 1965/66). O relevo do local é plano com inclinação em torno de 5\% e solo do tipo Latossolo Roxo. O teste foi instalado no delineamento experimental de blocos de famílias compactas, com seis repetições, sendo que nas parcelas estão alocadas as procedências e nas sub-parcelas as progênies com cinco plantas, totalizando 35 progênies. $\mathrm{O}$ espaçamento utilizado foi de $3 \times 3 \mathrm{~m}$. Também foi adotada uma bordadura externa de duas linhas da mesma espécie. Os ensaios foram mensurados aos 24 anos de idade para os caracteres diâmetro à altura do peito (DAP) $(\mathrm{cm})$; altura da planta $(\mathrm{m})$; volume cilíndrico $\left(\mathrm{m}^{3}\right)$, conforme a fórmula: $V C=\left[\pi\left(D A P^{2}\right) / 4\right] h$, sendo $D A P$ : diâmetro à altura do peito $(\mathrm{cm})$ e $h$ : altura total de planta (m); sobrevivência (\%) e, avaliada a forma do fuste, com notas: 1 - fuste muito tortuoso e bifurcado; 2 - fuste bifurcado e com tortuosidade acima da média; 3 - fuste com defeito bastante visível, sem bifurcação e com tortuosidade média; 4 - fuste com defeito pouco visível, sem bifurcação e com tortuosidade abaixo da média; 5 - fuste reto sem bifurcação, danos e doenças.

\section{Análise estatística}

As análises foram desenvolvidas no programa computacional genético-estatístico SELEGEN (Resende, 2007), utilizando o método de REML/BLUP (máxima verossimilhança restrita/melhor predição linear não viciada). A análise de deviance para diferenciar os tratamentos foi realizada primeiramente pelo modelo 93, para análise individual das procedências, e posteriormente pelo modelo 5, para análise conjunta (população experimental). Os modelos estatísticos usados foram: modelo 93: $\mathrm{y}=\mathrm{Xr}+\mathrm{Za}+\mathrm{Wp}+\mathrm{e}$, em que y é o vetor de dados, $r$ é o vetor dos efeitos de repetição (assumidos como fixos) somados à média geral, a é o vetor dos efeitos genéticos aditivos individuais (aleatórios), p é o vetor dos efeitos de parcelas (aleatórios), é o vetor de erros ou resíduos(aleatórios); modelo $5: \mathrm{y}=\mathrm{Xr}+\mathrm{Za}+\mathrm{Wp}+\mathrm{Ts}+\mathrm{e}$, em que y é o vetor de dados, r é o vetor dos efeitos de repetição (assumidos como fixos) somados à média geral, a é o vetor dos efeitos genéticos aditivos individuais (assumidos como aleatórios), p é o vetor dos efeitos de parcela (assumidos como aleatórios), s é vetor dos efeitos de população ou procedência (aleatórios), e e é o vetor de erros ou resíduos (aleatórios). As letras maiúsculas representam as matrizes de incidência para os referidos efeitos. Os parâmetros genéticos estimados foram: $\sigma_{a}^{2}=$ variância genética aditiva

$\sigma_{\text {parc }}^{2}=$ variância ambiental entre parcelas

$\sigma_{\text {proc }}^{2}=$ variância genética entre populações ou procedências

$\sigma_{e}^{2}=$ variância residual

$\sigma_{f}^{2}=$ variância fenotípica individual

$h_{a}^{2}=$ herdabilidade individual no sentido restrito, ou seja, dos efeitos aditivos

$h_{m p}^{2}=$ herdabilidade da média de progênies

$c_{\text {parc }}^{2}=$ coeficiente de determinação dos efeitos de parcelas

$c_{\text {proc }}^{2}=$ coeficiente de determinação dos efeitos de populações

$C V_{g i}=$ coeficiente de variação genética aditiva individual.

$C V_{g p}=$ coeficiente de variação genotípica entre progênies

$C V_{e}=$ coeficiente de variação residual

A correlação genética entre DAP e altura foi calculada de acordo com a expressão:

$$
\hat{r}_{g_{X Y}}=\frac{\hat{\sigma}_{P_{X} P_{Y}}}{\sqrt{\hat{\sigma}_{P_{X}}^{2} \hat{\sigma}_{P_{Y}}^{2}}}
$$

Em que $r_{g_{X}}$ é o coeficiente de correlação genética; $\sigma_{P_{X} P_{Y}}$ é o produtório genético entre progênies para os caracteres $x$ e $y ; \sigma_{P_{X}}^{2}$ e $\sigma_{P_{Y}}^{2}$ são as variâncias genéticas entre progênies/procedências dos caracteres $x$ e $y$, respectivamente. 


\section{Resultados e discussão}

\section{Variação genética}

$\mathrm{O}$ efeito de progênies foi significativo $(\mathrm{P} \leq 0,01)$ (Tabela 1) para os cinco caracteres silviculturais estudados da procedência de Bebedouro (12,43 para DAP; 20,56 para altura; 10,48 para volume cilíndrico e 33,06 para sobrevivência), com exceção da forma do fuste. Para a procedência de Mogi Guaçu ocorreu diferença significativa somente para forma do fuste $(17,64)$ e para a análise conjunta, onde todos os caracteres foram significativos. $\mathrm{O}$ efeito de procedência foi altamente significativo apenas para forma do fuste $(10,47)$, sugerindo que para este caráter há possibilidade de execução dos trabalhos com a variação genética para seleção entre procedências. Estes resultados destacam que a estratégia amostral foi efetiva para reter a variabilidade genética da população, além de indicar a possibilidade de manipulação da variação gênica pela seleção entre progênies das amostras avaliadas.

Tabela 1 .Análise de deviance (ANADEV) para os caracteres diâmetro à altura do peito (DAP), altura de planta (AP), volume cilíndrico (VC), forma do fuste (FOR) e sobrevivência (SOB) de Handroanthus vellosoi para cada procedência e para análise conjunta.

\begin{tabular}{|c|c|c|c|c|}
\hline Caracteres & Efeitos & Bebedouro & $\begin{array}{c}\text { Mogi } \\
\text { Guaçu }\end{array}$ & $\begin{array}{c}\text { Análise } \\
\text { Conjunta }\end{array}$ \\
\hline \multirow{3}{*}{$\begin{array}{l}\text { DAP } \\
(\mathrm{cm})\end{array}$} & Progênies & $12,43 * *$ & $0^{\mathrm{ns}}$ & $10,77^{* *}$ \\
\hline & Parcela & $0,74^{\text {ns }}$ & $0,01^{\text {ns }}$ & $0,16^{\mathrm{ns}}$ \\
\hline & Procedência & - & - & $0,03^{\text {ns }}$ \\
\hline \multirow{3}{*}{$\begin{array}{l}\text { AP } \\
(\mathrm{m})\end{array}$} & Progênies & $20,56^{* *}$ & $0,05^{\mathrm{ns}}$ & $14,02 * *$ \\
\hline & Parcela & $0,92^{\mathrm{ns}}$ & $0,05^{\mathrm{ns}}$ & $1,14^{\mathrm{ns}}$ \\
\hline & Procedência & - & - & $1,31^{\mathrm{ns}}$ \\
\hline \multirow{3}{*}{$\begin{array}{l}\mathrm{VC} \\
\left(\mathrm{m}^{3}\right)\end{array}$} & Progênies & $10,48^{* *}$ & $0,03^{\text {ns }}$ & $10,27^{* *}$ \\
\hline & Parcela & $0,15^{\text {ns }}$ & $0,03^{\text {ns }}$ & $0,23^{\mathrm{ns}}$ \\
\hline & Procedência & - & & $0^{\mathrm{ns}}$ \\
\hline \multirow{3}{*}{ FOR } & Progênies & $2,09^{\mathrm{ns}}$ & $17,64 * *$ & $18,46^{* *}$ \\
\hline & Parcela & $0,01^{\mathrm{ns}}$ & $0,04^{\mathrm{ns}}$ & $0,04^{\mathrm{ns}}$ \\
\hline & Procedência & - & - & $10,47 * *$ \\
\hline \multirow{3}{*}{$\begin{array}{l}\text { SOB } \\
(\%)\end{array}$} & Progênies & $33,06 * *$ & $3,52^{\mathrm{ns}}$ & $35,38^{* *}$ \\
\hline & Parcela & - & - & $1,09^{\mathrm{ns}}$ \\
\hline & Procedência & - & - & - \\
\hline
\end{tabular}

**: $\mathrm{P} \leq 0,01 ;{ }^{\text {ns: }}$ não significativo.

\section{Estimativas de parâmetros genéticos}

Os coeficientes de variação genética ( $C V_{g i}$ e $\left.C V_{g p}\right)$ foram moderados a altos (Tabela 2 ) para a procedência de Bebedouro, variando entre 19,6\% (forma do fuste) e 78,8\% (volume cilíndrico), baixos a moderadamente altos para a procedência de Mogi Guaçu, variando entre $1,9 \%$ (DAP) e $28,8 \%$ (forma do fuste), assim como para análise conjunta, variando entre 2,3\% (altura de planta) e $51 \%$ (volume cilíndrico). Os resultados obtidos para estas populações de $H$. vellosoi, segundo a análise conjunta, estão dentro do padrão de variação observado para outras espécies arbóreas estudadas por caracteres quantitativos, como Araucaria angustifolia (Sebbenn et al., 2003, 2004), Balfoudendron riedelianum (Sebbenn et al., 2007) e Myracrodruon urundeuva (Freitas et al., 2006).

Os valores do coeficiente de variação experimental $\left(C V_{e}\right)$ foram considerados médios a altos para a procedência de Bebedouro, com valores variando entre $16,8 \%$ (altura) e 55,3\% (volume cilíndrico), para a procedência de Mogi Guaçu, com valores variando entre $15,2 \%$ (altura) e 38,5\% (volume cilíndrico) e análise conjunta, com valores variando entre $18,5 \%$ (altura) e 46,9\% (volume cilíndrico). A magnitude do $C V_{e}$ esta associada a precisão experimental e forma de mensuração dos caracteres. $\mathrm{O}$ volume cilíndrico em geral apresenta maiores valores de $C V_{e}$ devido ao fato de ser um caráter estimado de outros dois caracteres, o DAP e a altura, acumulando os erros de mensuração destes dois. Por exemplo, Freitas et al. (2006) estudando progênies de polinização aberta de Cordia trichotoma aos 19 anos de idade, também na Estação Experimental de Luiz Antônio, observaram valores de $C V_{e}$ baixo para altura total $(10,1 \%)$, médio para DAP $(20,8 \%)$ e alto para volume (37,6\%). Sebbenn et al. (2003) estudando procedências de Grevillea robusta aos 11 anos de idade, na Estação Experimental de Avaré, observou valores de $C V_{e}$ baixo para altura total $(13,9 \%)$, médio para DAP $(24,0 \%)$ e alto para volume cilíndrico $(54,4 \%)$. Logo, os valores de $C V_{e}$ estimados no presente trabalho estão dentro do padrão observado em outros estudos similares.

Segundo Resende (2002), o ideal para estimativas do coeficiente de determinação dos efeitos de parcela $\left(C_{\text {parc }}^{2}\right.$ ) são valores iguais ou inferiores a $10 \%$. Em concordância, em todos os caracteres estudados, os valores foram menores que $10 \%$. Observando os resultados para o coeficiente de determinação dos efeitos de parcela obtidos por Guerra et al. (2009), estudando 
duas populações de Myracrodruon urundeuva, para o caráter altura, os autores obtiveram estimativas de $11,7 \%$ a $33,3 \%$, que foi muito superior aos obtidos neste trabalho. Uma possível explicação para os maiores valores observados por Gerra et al. (2009) é o fato de que os testes de progênies de Myracrodruon urundeuva, não eram ensaios puros, mas sim, testes mistos (Myracrodruon urundeuva e Trema micrantha), o que pode ter reduzido a precisão experimental dentro das parcelas.

A estimativa da herdabilidade demonstra que o papel preditivo de expressar a confiança do valor fenotípico ou o grau de correspondência entre o valor fenotípico e genético (Falconer, 1987; Vencovsky \& Barriga, 1992) no sentido restrito, proporciona o conhecimento sobre a magnitude relativa das variações genética e ambiental. As estimativas de herdabilidade foram altas, no sentido restrito e da média de progênies para todos os caracteres avaliados na procedência de Bebedouro, com exceção do caráter forma do fuste $(0,13)$. Essa mesma avaliação realizada para as procedências de Mogi Guaçu demonstraram valores baixos em geral, com herdabilidade alta, no sentido restrito, apenas para o caráter forma do fuste $(0,46)$. $\mathrm{Na}$ análise conjunta, as estimativas de herdabilidade foram medianas a altas, no sentido restrito, para todos os caracteres, DAP $(0,26)$, altura $(0,32)$, volume cilíndrico $(0,24)$, forma $(0,27)$ e sobrevivência $(0,46)$, indicando que parte da variação fenotípica total e média entre progênies são de origem genética. Portanto, a variabilidade genética para os caracteres estudados, para as herdabilidades em destaque, com valores medianos a altos podem ser exploradas em programa de melhoramento genético para os caracteres em estudo e para conservação genética. Este resultado também indica que os caracteres têm potencial genético para responder à seleção natural, ou seja, a média das populações pode ser alterada pela seleção natural. Em geral, estimativas de herdabilidades individuais conduzem a moderadas magnitudes das herdabilidades em nível de médias de família (Resende, 2002). Falconer (1987) observou que a herdabilidade é uma propriedade não somente de um caráter, mas também da população e das circunstâncias de ambientes às quais os indivíduos estão sujeitos. O valor da herdabilidade poderá ser afetado se houver alteração em qualquer um dos componentes da variância. Assim, estes altos coeficientes de herdabilidade indicam expressivo controle genético sobre os caracteres avaliados. Com isso, é possível inferir que os caracteres estudados de H. vellosoi podem ser utilizados para avaliação da variabilidade genética de populações amostradas da espécie, ressaltando que a procedência de Bebedouro tem maior potencial genético.

O incremento médio anual (IMA) estimado para os caracteres de crescimento em DAP e altura, estudados aos 24 anos de idade, para a procedência Bebedouro foram de 0,58 cm e 0,42 $\mathrm{m}$, para a procedência Mogi Guaçu foram de $0,62 \mathrm{~cm}$ e $0,46 \mathrm{~m}$, e para a análise conjunta foram de $0,60 \mathrm{~cm}$ e $0,44 \mathrm{~m}$, respectivamente. Em relação às espécies arbóreas nativas, os valores são medianos aos observados por Freitas et al. (2007) em progênies de Gallesia integrifolia, aos 20 anos de idade $(\mathrm{DAP}=1,09 \mathrm{~cm}$ e altura $=0,68 \mathrm{~m}$ ) e em progênies de $M$. urundeuva, aos 17 anos de idade $(\mathrm{DAP}=0,77 \mathrm{~cm}$ e altura $=0,68 \mathrm{~cm})$, sendo que esses ensaios foram instalados na Estação Experimental de Luiz Antônio, com as mesmas condições climáticas e de solo. Esses resultados indicam que o material procedente de Bebedouro apresentou melhor desempenho para os caracteres de crescimento, mas que se trata de espécie de crescimento lento.

Por sua vez, o caráter forma do fuste apresentou desempenho médio muito semelhante para as duas procedências do ensaio. Considerando que a forma do fuste é medida com notas, que variam de 1 (pior) a 5 (melhor forma de fuste), a magnitude dos valores obtidos $(>2)$, demonstra que ambas as populações apresentaram forma mediana para a exploração da madeira, ou seja, o tronco possui defeito bastante visível e tortuosidade média. Todavia, a sua exploração nesse caso seria mais apropriada para outra finalidade, como por exemplo, energia. Comparando-se os resultados com a literatura, observa-se que os dados obtidos nesses experimentos foram próximos aos obtidos por diversos autores com espécies nativas. Por exemplo, utilizando a mesma classificação de notas do presente estudo, Freitas et al. (2006) observaram valores abaixo da nota 3 para população de Myracrodruon urundeuva e Freitas et al. (2008) para duas populações de Handroanthus heptaphyllus, encontraram notas abaixo de 2 . 


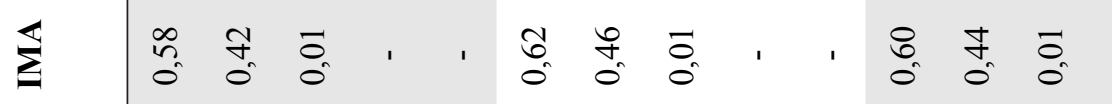

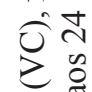

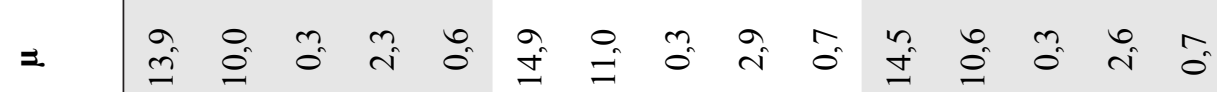

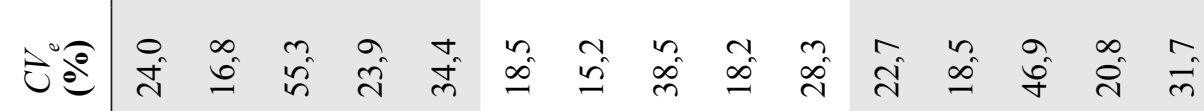

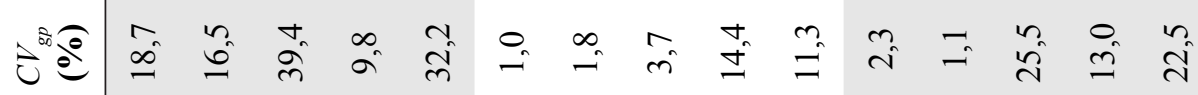

这焉

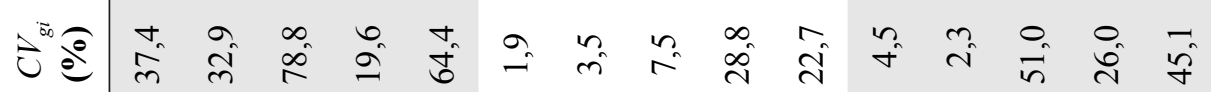

ש

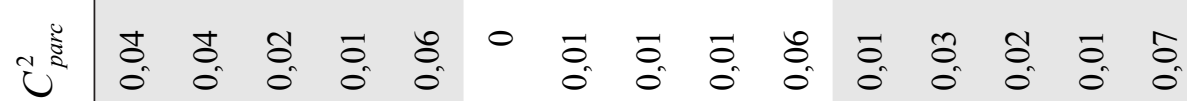

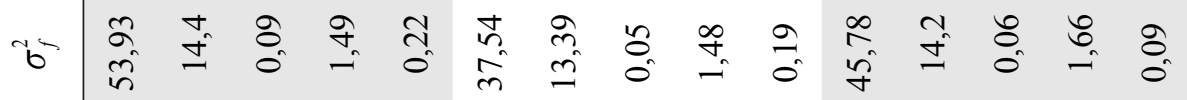

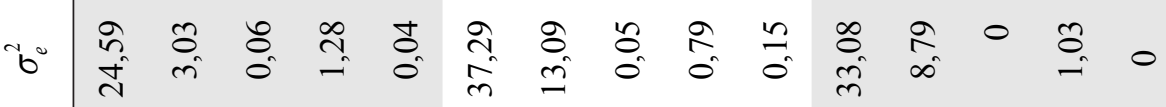

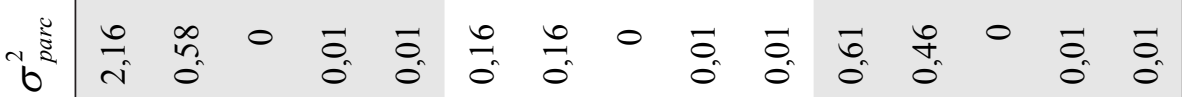




\section{Correlação genética}

As correlações foram estimadas apenas em nível do experimento, desconsiderando o efeito de procedências. A correlação genética foi positiva, altamente significativa entre os caracteres DAP e altura $(0,91 ; \mathrm{P}<0,01)$, mostrando fortes efeitos pleiotrópicos entre estes caracteres ou efeito de ligação gênica entre os locos, controlando o desenvolvimento destes caracteres. Assim, a possibilidade de seleção em um caráter e a obtenção de ganhos indiretos em outro é relativamente alta, ou seja, DAP é um bom preditor do desempenho em altura. Em geral se observa em espécies arbóreas altas correlações genéticas entre DAP e altura, como verificado neste trabalho.

\section{Conclusões}

Existe variação genética entre procedências somente para o caráter forma do fuste e entre progênies dentro de procedências para todos os caracteres, sendo que a maior parte da variação genética detectada encontra-se distribuída entre progênies.

Em geral, as herdabilidades moderadas para os caracteres avaliados na análise conjunta indicam que a população tem potencial genético para responder à seleção natural, assim como para a conservação genética ex situ e utilidade para exploração em programas de melhoramento genético.

\section{Agradecimentos}

Os autores são gratos a Antenor Oliveira da Silva, Paulo Teodoro Ferreira e Jair Rodrigues, pelo apoio à mensuração do experimento. À Fundação de Amparo à Pesquisa do Estado de São Paulo pela concessão de Bolsa de mestrado (Processo 2010/01548-1). Os autores MAS e MLTM também agradecem ao Conselho Nacional de Desenvolvimento Científico e Tecnológico - CNPq pela concessão da bolsa de Produtividade em Pesquisa e pelo Auxilio Pesquisa Processo 402026/2008-0.

\section{Referências}

CARVALHO, P. E. R. Espécies florestais brasileiras: recomendações silviculturais, potencialidades e uso da madeira. Brasília, DF: EMBRAPA-CNPF/SPI, 1994. 640 p.

FALCONER, D. S. Introdução à genética quantitativa. Viçosa, MG: Universidade Federal de Viçosa, 1987. 279 p.

FREITAS, M. L. M.; AUKAR, A. P. A.; SEBBENN, A. M.; MORAES, M. L. T.; LEMOS, E. G. M. Genetic variation in progenies of Myracrodruon urundeuva F.F. e M.F. Allemao in three cultivation systems. Revista Árvore, Viçosa, MG, v. 30, n. 3, p. 319-329, 2006 a.

FREITAS, M. L. M.; SEBBENN, A. M.; MORAES, E.; ZANATTO, A. C. S.; VERADI, C. K.; PINHEIRO, A. N. Parâmetros genéticos em progênies de polinização aberta de Cordia trichotoma (Vell.) ex Steud. Revista Instituto Florestal, São Paulo, v. 18, p. 95-102, 2006b.

FREITAS, M. L. M.; SEBBENN, A. M.; ZANATTO, A. C. S.; MORAES, E. Formação de pomar de sementes a partir da seleção dentro de teste progênies de Myracrodruon urundeuva. Revista Instituto Florestal, São Paulo, v. 19, n. 2, p. 65-72, 2007.

FREITAS, M. L. M.; SEBBENN, A. M.; ZANATTO, A. C. S.; MORAES, E.; MORAES, M. A. Variação genética para caracteres quantitativos em população de Gallesia integrifolia (Spreng.) Harms. Revista Instituto Florestal, São Paulo, v. 20, n. 2, p. 165-173, 2008.

FREITAS, M. L. M.; SEBBENN, A. M.; ZANATTO, A. C. S.; MORAES, E.; HAYASHI, P. H.; MORAES, M. A. Variação e parâmetros genéticos em dois bancos de germoplasma de Tabebuia heptaphylla (Velloso) Toledo. Revista Instituto Florestal, São Paulo, v. 20, n. 1, p. 13-22, 2008.

GUERRA, C. R. S. B.; MORAES, M. L. T.; SILVA, C. L. S. P.; CANUTO, D. S. O.; ANDRADE, J. A. da C.; FREITAS, M. L. M.; SEBBENN, A. M. Estratégias de seleção dentro de progênies em duas populações de Myracrodruon urundeuva Fr. All. Scientia Forestalis, Piracicaba, v. 37, n. 81, p. 79-87, 2009.

HAUGERUD, A.; COLLINSON, M. P. Plants genes and people: improving the relevance of plant breeding in Africa. Experimental Agriculture, Cambridge, v. 26, p. 341-362, 1990.

KAGEYAMA, P. Y. Conservação "in situ” de recursos genéticos de plantas. IPEF, Piracicaba, n. 35, p. 7-37, 1987.

LORENZI, H. Árvores brasileiras: manual de identificação e cultivo de plantas arbóreas nativas do Brasil. Nova Odessa: Plantarum, 1992. 352 p.

NASS, L. L.; VALOIS, A. C. C.; MELO, I. S.; VALADARESINGLIS, M. C. (Ed.) Recursos genéticos e melhoramento de plantas. Rondonópolis: Fundação MT, 2001.

NANSON, A. The provenance seedling seeds orchards. Silvae Genetica, Frankfurt, v. 21, p. 243-249, 1972. 
PINTO, S. I. C.; SOUZA, A. M.; CARVALHO, D. Variabilidade genética por isoenzimas em populações de Copaifera langsdorffi Desf. em dois fragmentos de mata ciliar. Scientia Forestalis, Piracicaba, v. 1, n. 65, p. 40-48, 2004.

RESENDE, M. D. V. de. Genética biométrica e estatística no melhoramento de plantas perenes. Brasília, DF: Embrapa Informação Tecnológica; Colombo: Embrapa Florestas, 2002. 975 p.

RESENDE, M. D. V. de. Software SELEGEN - REML/BLUP: sistema estatístico e seleção genética computadorizada via modelos lineares mistos. Colombo: Embrapa Florestas, 2007. 360 p.

SEBBENN, A. M.; AOKI, H.; MORAES, M. L. T. Variação genética e seleção em teste de procedências de Grevillea robusta A. Cunn.. Revista Instituto Florestal, São Paulo, v. 15, n. 1, p. 1-8, 2003 a.

SEBBENN, A. M.; PONTINHA, A. A. S.; GiAnOtTi, E.; KAGEYAMA, P. Y. Genetic variation in provenance-progeny test of Araucaria angustifolia in São Paulo state, Brazil. Silvae Genetica, Frankfurt, v. 52, p. 181-184, 2003 b.
SEBBENN, A. M.; PONTINHA, A. A. S.; FREITAS, S. A.; FREITAS, J. A. Variação genética em cinco procedências de Araucaria angustifolia (Bert.) O. Ktze. no sul do Estado de São Paulo. Revista Instituto Florestal, São Paulo, v. 16, n. 2, p. 91-99, 2004.

SEBBENN, A. M.; FREITAS, M. L. M.; ZANATTO, A. C. S.; MORAES, E.; MORAES, M. A. Conservação ex situ e pomar de sementes em banco de germoplasma de Balfourodendron riedelianum. Revista Instituto Florestal, São Paulo, v. 19, n. 2, p. 101-112, 2007.

SIMONS, A. J. Genetic improvement of non-industrial trees. Agroforestry Systems, Dordrecht, v. 8, p. 197-212, 1992.

VENCOVSKY, R.; BARRIGA, P. Genética biométrica no fitomelhoramento. Ribeirão Preto: Sociedade Brasileira de Genética, 1992. 486 p.

VENTURA, A.; BERENGUT, G.; VICTOR, M.A. M. Características edafo-climáticas das dependências do Serviço Florestal do Estado de São Paulo, Silvicultura, São Paulo, v. 4, p. 57-140, 1965/66. 